\title{
Prosthetic Knee Joint Infection due to Salmonella Species: A Case Report
}

\author{
Ali Ghaffar ${ }^{1}$, Malik Hatim Hussain ${ }^{1}$, Rama Mohan ${ }^{2}$ \\ 1. Orthopaedics and Trauma, East Lancashire NHS Hospitals, Blackburn, GBR 2. Trauma and Orthopaedics, North \\ Manchester Hospital, Manchester, GBR
}

Corresponding author: Malik Hatim Hussain, hatimhussain092@gmail.com

\begin{abstract}
We present a case of a 79-year-old male with a Salmonella enteritidis prosthetic knee joint infection preceded by an episode of profuse diarrhea. The infection was treated with ceftriaxone antibacterial chemotherapy, and an arthroscopic knee joint washout. The initial treatment failed to eradicate the Salmonella infection. A second open washout procedure with the replacement of knee joint insert was performed along with the addition of ciprofloxacin to the ongoing ceftriaxone which eventually eradicated the infection. Although S. enteritidis is a very rare cause of prosthetic knee infection, suspicion of Salmonella as a potential causative agent should be borne in mind particularly if the onset of the symptoms is preceded by gastrointestinal manifestations.
\end{abstract}

Categories: Orthopedics, Rheumatology

Keywords: septic arthritis, prosthetic joint infection, salmonella

\section{Introduction}

Besides improving the quality of life, joint replacements are considered as life-enhancing surgical procedures [1]. About 719000 knee replacements were performed in the United States in 2010 alone [2]. According to previous reports, $1 \%-2 \%$ of joint replacements eventually become infected [3]. Prosthetic joint infection/periprosthetic joint infection involves prosthesis and adjacent tissues [1]. While Gram-positive Staphylococcus is a common culprit, enteroinvasive Gram-negative organisms (Salmonella) can rarely infect replacement prosthesis, especially in immunocompromised individuals [4-5]. We report a case of a prosthetic joint infection caused by Salmonella enteritidis in an immunocompetent male.

\section{Case Presentation}

A 79-year-old male presented with pain and swollen left knee. He was febrile and unable to weight bear on the left knee joint. There was no history of trauma. He had recently returned from a holiday in Cuba a few days prior to the presentation. Whilst in Cuba, he developed profuse diarrhea which spontaneously resolved within three days. This was soon followed by acute onset of mild, progressively worsening, left knee pain.

Received 05/19/2020

Review began 05/27/2020 Review ended 06/02/2020 Published 06/09/2020

\section{() Copyright 2020}

Ghaffar et al. This is an open access article distributed under the terms of the Creative Commons Attribution License CC-BY 4.0., which permits unrestricted use, distribution, and reproduction in any medium, provided the original author and source are credited.
His past medical history was significant for atrial fibrillation, mild aortic stenosis, benign prostatic hyperplasia, and bilateral total knee arthroplasty. A cruciate retaining left total knee arthroplasty was performed in 2004. Postoperative recovery was satisfactory and normal limb function was achieved.

At the time of his current admission, the temperature was $38.6^{\circ} \mathrm{C}$. Initial blood investigations showed a white cell count (WCC) of $14.5 \times 109 / \mathrm{L}$ and C-reactive protein (CRP) $229 \mathrm{mg} / \mathrm{dL}$. On examination, moderate amount of effusion was noted in the left knee joint along with erythema over the joint. Range of movement in the left knee was restricted, systemic examination was unremarkable. Aspiration fluid was turbid and cultures grew $S$. enteritidis which was sensitive to ceftriaxone and ciprofloxacin. The patient was commenced on ceftriaxone ( $2 \mathrm{~g} / 24$ hours IV) and fasted in preparation for arthroscopic knee washout on the following day.

An arthroscopic washout was performed and approximately $150 \mathrm{~mL}$ of pus was drained. Following this, the CRP showed mild degree of improvement, meanwhile WCC increased to $16.5 \times 109 / \mathrm{L}$ on the day 3 of the washout. Clinically the knee remained painful and swollen, and the temperature was $37.3^{\circ} \mathrm{C}$. Ceftriaxone therapy was continued throughout this time. Poor response to the initial washout led to a decision to perform an open surgical washout with polyethylene insert exchange. Following this, both the CRP and WCC showed drastic improvements. As per recommendations by the infectious diseases team, ciprofloxacin (750 $\mathrm{mg} \mathrm{BD}, \mathrm{PO}$ ) was also added to the existing IV ceftriaxone therapy to ensure complete extermination of $S$. enteritidis. On day 13 following the washout, WCC was 9.4 x 109/L and CRP $97 \mathrm{mg} / \mathrm{dL}$. The patient was pain free and apyrexic. Joint swelling had disappeared. The patient was subsequently discharged.

The patient was in good clinical condition at the three-month follow-up. The laboratory findings and knee examination were all normal with a pain-free range of movement of $0^{\circ}-110^{\circ}$. 


\section{Discussion}

Prosthetic joint infection is a rare phenomenon. It has been previously reported that only about $1 \%-2 \%$ of all cases involving a prosthetic joint become infected. Staphylococcus is responsible for the majority of the cases [3]. Conditions such as rheumatoid arthritis, systemic lupus erythematosus (SLE), sickle cell disease, and HIV appear to be associated with a relatively higher frequency of Salmonella bacteremia and septic arthritis [6].

Salmonella is contracted through fecal-oral route. Gastrointestinal complications are more common manifestation due to $S$. enteritidis infection [7].

In the present case, there were no indications that the patient was immunocompromised, either iatrogenically or as a result of a medical condition. Focal Salmonella infection of the left knee joint is likely to have occurred due to occult bacteremia during the preceding episode of diarrhea.

Our patient had successful outcomes from a combination of antibacterial therapy and surgical intervention that also involved polyethylene insert exchange. The need to fortify antibacterial therapy with a combination of two drugs raises concerns of drug resistance in $S$. enteritidis.

\section{Conclusions}

In conclusion, although S. enteritidis is a very rare cause of prosthetic joint infection, the possibility of prosthetic joint infection caused by $S$. enteritidis should be borne in mind especially when patients present with history of gastrointestinal complications or recent travel.

\section{Additional Information}

\section{Disclosures}

Human subjects: Consent was obtained by all participants in this study. Conflicts of interest: In compliance with the ICMJE uniform disclosure form, all authors declare the following: Payment/services info: All authors have declared that no financial support was received from any organization for the submitted work. Financial relationships: All authors have declared that they have no financial relationships at present or within the previous three years with any organizations that might have an interest in the submitted work. Other relationships: All authors have declared that there are no other relationships or activities that could appear to have influenced the submitted work.

\section{References}

1. Tande AJ, Patel R: Prosthetic joint infection. Clin Microbiol Rev. 2014, 27:302-345. 10.1128/CMR.00111-13

2. National hospital discharge survey: 2010 table, procedures by selected patient characteristics. Centers for Disease Control and Prevention, Atlanta, GA. (2013). https://www.cdc.gov/nchs/data/nhds/4procedures/2010pro4_numberprocedureage.pdf.

3. Izakovicova P, Borens O, Trampuz A: Periprosthetic joint infection: current concepts and outlook. EFORT Open Rev. 2019, 4:482-494. 10.1302/2058-5241.4.180092

4. Le Dantec L, Maury F, Flipo RM, Laskri S, Cortet B, Duquesnoy B, Delcambre B: Peripheral pyogenic arthritis. A study of one hundred seventy-nine cases. Rev Rhum Engl Ed. 1996, 63:103-110.

5. Goldenberg DL, Brandt KD, Cathcart ES, Cohen AS: Acute arthritis caused by gram-negative bacilli: a clinical characterization. Medicine (Baltimore). 1974, 53:197-208. 10.1097/00005792-197405000-00003

6. Lavy CB: Septic arthritis in Western and sub-Saharan African children - a review . Int Orthop. 2007, 31:137144. 10.1007/s00264-006-0169-9

7. Waldner LL, MacKenzie KD, Köster W, White AP: From exit to entry: long-term survival and transmission of Salmonella. Pathogens. 2012, 128:155. 10.3390/pathogens1020128 